\title{
Study on a desktop machine tool for micromilling
}

\author{
X. Cheng ${ }^{1, a^{*}}$, J.C. Liü ${ }^{2, b}$, G.M. Zheng ${ }^{1, c}$, R.F. Xü ${ }^{1, d}$ \\ ${ }^{1}$ School of Mechanical Engineering, Shandong University of Technology, Zibo, 255049, China \\ ${ }^{2}$ School of Engineering and Computer Science, University of the Pacific, Stockton, 95211, USA \\ aemail: happychengx@163.com, bemail: jliu@pacific.edu, `email: zhengguangming@sdut.edu.cn \\ demail: xurufeng2013@126.com
}

Keywords: Micromilling, FEM, Desktop machine tool, Surface roughness.

\begin{abstract}
Mechanical micromilling is the key technique for the fabrications of high quality miniaturized components with nano-level surface roughness by only one-time workpiece setup. Micromilling machine tool is the prerequisite for this technique. A three-axis desktop micromilling machine tool has been developed and evaluated in the paper. The analysis shows that the stiffness of individual part affects the dynamics of the whole machine tool with different magnitudes and can be identified for the accurate assembling purpose. Experiments testify micromachining feasibility of the developed three-axis desktop machine tool. Further micromilling experiments are conducted on the brass material H59 which is widely used in fluid components. It turns out that the radial depth of cut affects the surface roughness most greatly in top surface micromilling of brass H59. The feed and the radial depth of cut have less significance on that.
\end{abstract}

\section{Introduction}

Miniature components are preferred for their smaller sizes, lower consumptions of materials and energy, and higher space utilization, etc. Furthermore, they adapt to the increasingly requirements of energy saving and environmental protection. In 2005, the total turnover of micro products is anticipated to reach US\$ 38 billion, which is two times of the total turnover in 2000 [1]. It is a general awareness that floor space and energy will be saved greatly while small-sized equipments are applied in the fabrications of miniature components[2]. It has turned out that energy consumption of desktop machine tools can reach $2 \%$ of that consumed by conventional machine tools for the same miniature parts with the same accuracy [3]. Furthermore, vibration and various errors can be reduced for small-sized machine tools $[4,5,6]$. Therefore, desktop machine tools as a kind of small-sized machines will be highly demanded in the near future for miniature components fabrications.

Among various types of desktop machine tools, micromilling ones is the most favorite for creating intricate 3D geometries regardless of their materials [7]. The design theories of desktop machine tools are still in the primitive stage [8]. Aiming at micro end-milling of miniature components, a three-axis desktop milling machine tool is introduced in the paper.

Micromilling process parameter is another aspect affecting the machined quality. In [9], designed experiments were used to study the parameters on the performance of the tools. In [10], large force variations were observed as the diameter of the cutter decreased and the spindle speed increased in studies on meso/micro milling. In [11], axial depth of cut, feed and spindle speed were studied on the surface roughness. Although it is concluded the machining parameters are less important than machine tools and cutters [12], the only way to improve the process and obtain the required quality and productivity is to adjust the micromilling process parameters.

The finished surface roughness is used as the criterion in the paper. Based on the introduced machine tool and further experiments, the three key process parameters of the axial depth of cut, the radial depth of cut, and the feed in micromilling of the very important engineering material brass H59 
are experimentally studied. The results can be used to guide the selection of process parameters in micromilling of brass materials given the milling system and workpiece.

\section{Desktop machine tool design}

The schematic design of the three-axis desktop micromilling machine tool is shown in Fig. 1. Considering the fact that totally twelve errors exist for a three-axis milling machine tool, motion transmissions, the feedback accuracy, and the assembly accuracy are very important aspects affecting the realization of a sub-micron accuracy for a micromilling machine tool [13]. The first two aspects can be realized by reasonably selecting the commercially available motion unit and the feedback unit. The assembly aspect can be realized in a reasonable accuracy range by assembling the machine tool corresponding to the structural analysis. Therefore, how to promise the accuracy in principle is very important. Detailed configurations are as follows. All three linear axes are driven by linear motors and supported by linear guideways. Natural granite is selected as the bed material. Kollmorgen linear motors are used for the three linear axes. The continuous thrusting forces for $\mathrm{Y}$ and $\mathrm{Z}$-axe linear motors IC11-50A are $502 \mathrm{~N}$ and that for X-axis linear motor IC11-75A is $754 \mathrm{~N}$. Renishaw linear encoders SRG20A with the resolution of $5 \mathrm{~nm}$ are used for feedback. The guide ways use THK ultra-stiffness and super precision cross-roller linear guide ways SRG 20A. PMAC motion cards together with a computer are used as the controlling unit. The spindle is an air bearing and air driven high-speed spindle NSK-Nakanishi ABS800 with the maximum rotational speed of 80,000rpm and a nominal radial run-out smaller than $1 \mu \mathrm{m}$. Two air-bearing cylinders are used for the gravity balancing of the $\mathrm{Z}$ axis components. The workspace is $100 \mathrm{~mm} \times 100 \mathrm{~mm} \times 100 \mathrm{~mm}$.

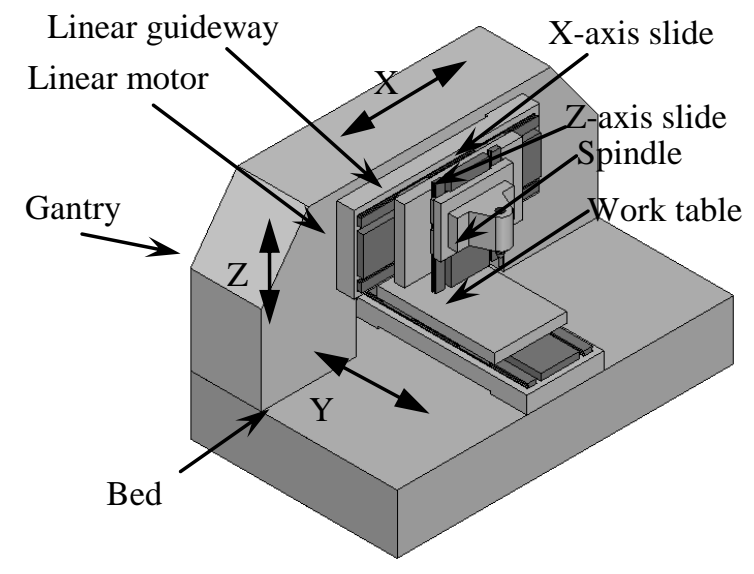

Fig. 1. Schematic design of the 3 -axis machine tool

The tiny cutting force in micromilling can be neglected for the design purpose. Therefore, the analytical loads acting on the machine tools are mainly the gravity and the attraction force generated by linear motors. Since three key parts as the gantry, the $\mathrm{X}$-axis slide, and the Z-axis slide as shown in Fig. 1, the static and dynamic performances of the designed desktop machine tool are mainly affected by these three key parts. Based on FEM, these parts are analyzed and optimized.

The quadratic tetrahedron mesh type is applied to the stiffness analysis. The material properties for the steel parts are that the Young's Modulus is $206 \mathrm{GPa}$, the density is $7850 \mathrm{Kg} / \mathrm{m} 3$, and the poisson ratio is 0.3 . The analysis results of $\mathrm{X}$-axis slide are shown in Fig. 2, where three kinds of geometries before and after optimizations for each part are included. It can be seen that the deformations of final optimized parts are all smaller than $1 \mu \mathrm{m}$.

The deformation of the whole machine tool after the optimization of the key parts has been analyzed and the maximum deformation is within $1 \mu \mathrm{m}$. The analytical results can be used to pre-adjust the assembly surface of the Z-axis to counterbalancing the possible deformations. 


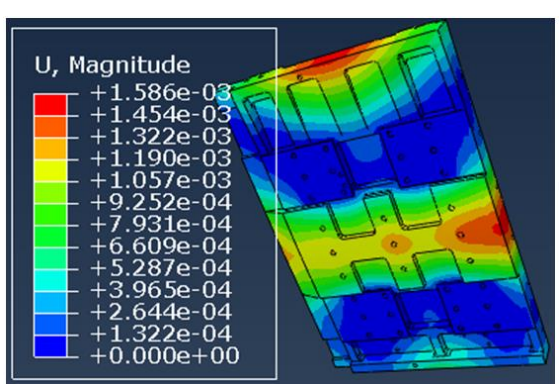

(a) X slide 1

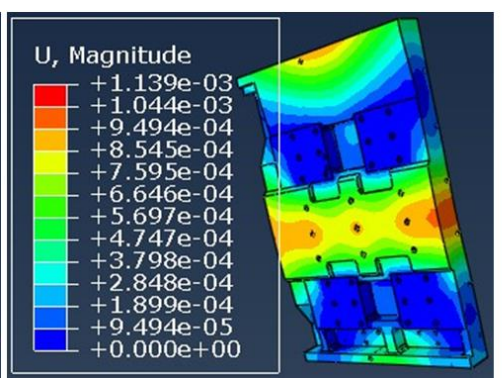

(b) $\mathrm{X}$ slide 2

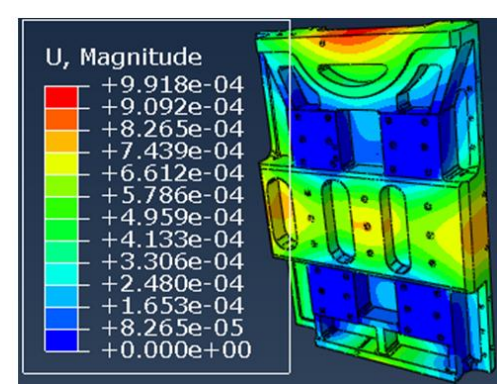

(c) $\mathrm{X}$ slide 3

Fig. 2. Stiffness analysis results

For machine tools with a high precision, the frequency of the first several modes are very important for achieving good dynamics performances. The analysis results show that the frequency of the first mode increases with the increase of the stiffness in a monotonic mode for each part. But the same tendency from other modes cannot be seen. The average frequencies are larger for parts with higher stiffness. Therefore, the analytical results can be used to evaluate the dynamics of the designed machine tool.

Modal analysis of the designed machine tool has been conducted and the results are shown in Fig. 3. The gantry has the largest effect on the whole machine's dynamics since the final frequency of the each mode is larger than that of the gantries with lower stiffness. The $\mathrm{Z}$ slide has the minimum effect on the whole machine's dynamics since the frequency is commensurate with each other.

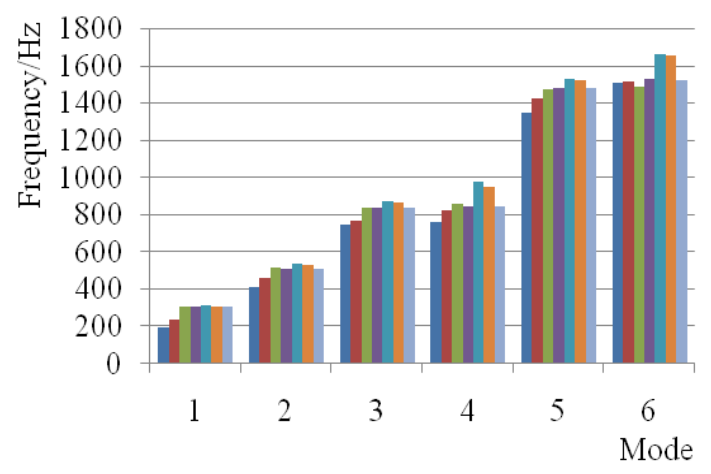

Fig. 3. Modal analysis of the whole machine tool

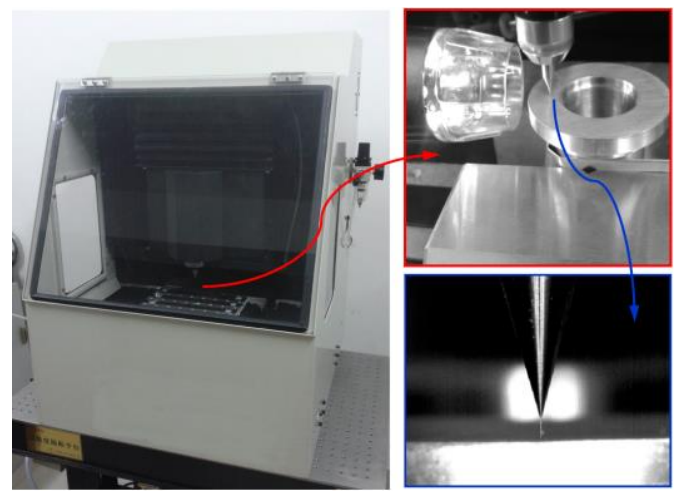

Fig. 4. Prototype of the developed machine

\section{Prototype development}

The prototype of the designed desktop micromilling machine tool 3A-S100 is shown in Fig. 4. By the Renishaw laser interferometer, the positioning accuracy has been measured and compensated. After measurement by the laser interferometer, it shows a very good zero-point identification accuracy falling in single-nano-meter level. $\mathrm{X}$ axis has been taken as an example to show the results before and after the compensation in Fig. 5 (a) and (b), respectively. The final positioning accuracy of each axis is smaller than $0.5 \mu \mathrm{m}$ and the repeatability is smaller than $0.1 \mu \mathrm{m}$. 


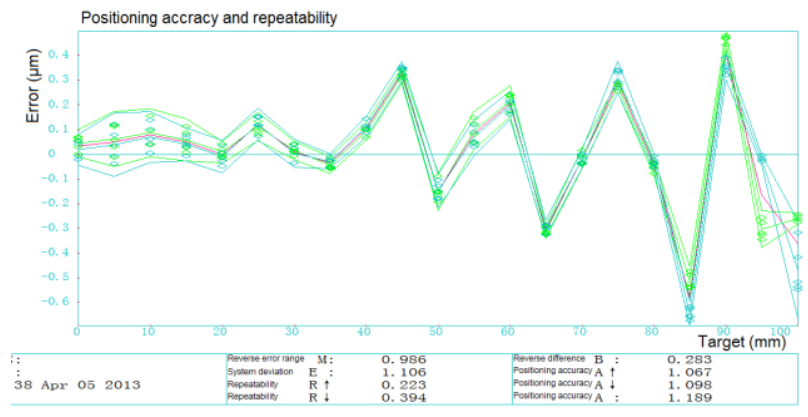

(a) Before compensation

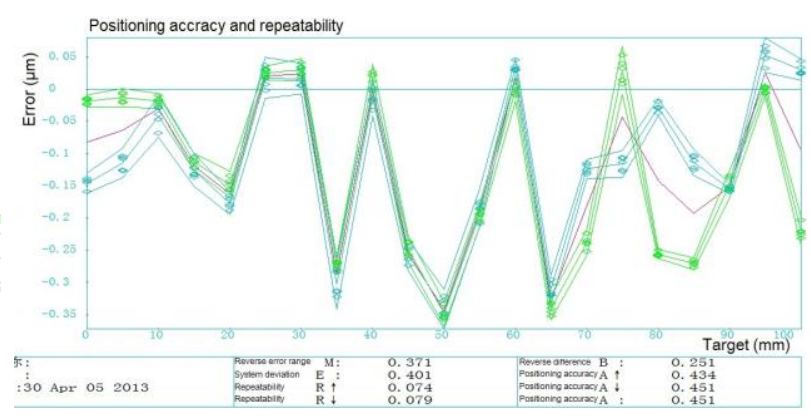

(b) After compensation

Fig. 5. Accuracy measurement and compensation

\section{Experiment}

Six through holes with the dimensions of $1 \mathrm{~mm}$ and $10 \mathrm{~mm}$ in diameter and depth are milled respectively. Two-flute micromilling cutter is made of tungsten carbide with the diameter of $0.5 \mathrm{~mm}$. The micromilled workpiece and the cutter are shown in Fig. 6 (a). Twelve micro holes with the diameter of $50 \mu \mathrm{m}$ and depth of $150 \mu \mathrm{m}$ on the end surface are micro milled with the conservative process parameters of $a_{p}=10 \mu \mathrm{m}, a_{e}=100 \mu \mathrm{m}$, and $f_{z}=0.1 \mu \mathrm{m} / \mathrm{rev}$-tooth. The mciro cutter is made of tungsten carbide without coating. The diameter of the cutter is also $50 \mu \mathrm{m}$. Fig. 6 (b) shows the tool-workpiece engagement and final machine result with a comparison of human hair.

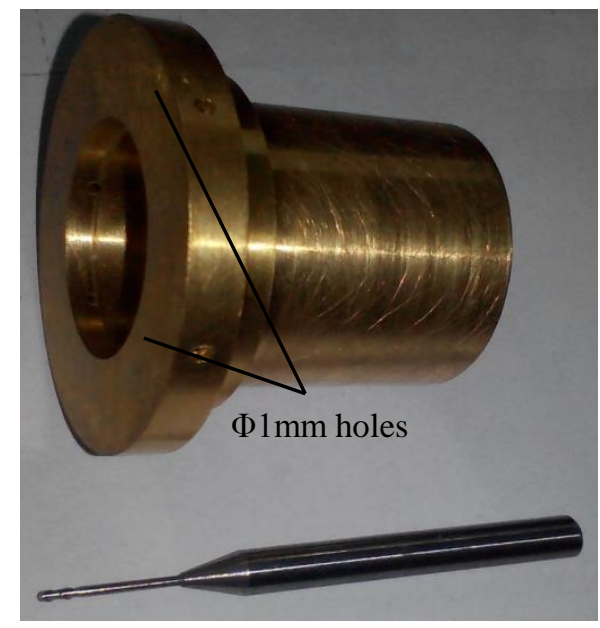

(a) Meso holes and the cutter

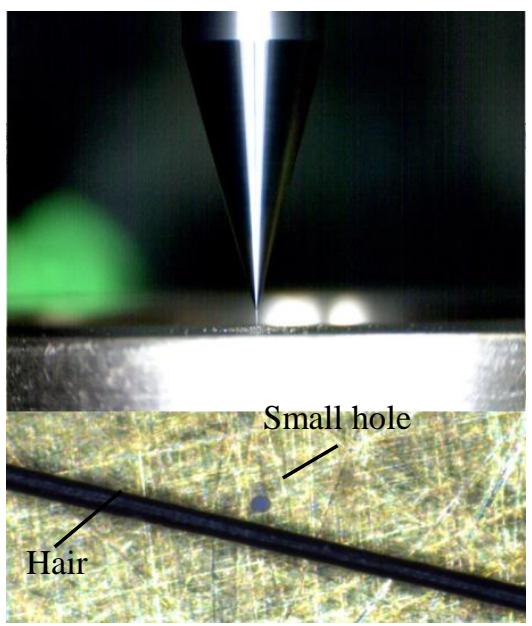

(b) Micro holes and the cutter

Fig. 6 Micromilling experiments

Totally eighteen experiments have been processed. The top surface roughness data measured are used for the analysis. Fig. 7 shows that the average surface finish can reach nano-leve in Ra. The analysis of the experimental results shows, for brass H59, the surface roughness becomes smaller and then larger while the axial depth of cut becomes larger and larger. There is an optimal axial depth of cut value $(10 \mu \mathrm{m})$ for an optimal surface roughness. For the radial depth of cut and the feed, it seems the smaller the better for achieving better surface roughness. The phenomena show the minimum chip thickness effect for the bottom cutting edges in micromilling. But for the side cutting edges, it is a combined effect actually for the minimum chip thickness effect. It is not revealed in the experiments, but further more experiments may demonstrate that. For micromilling parameters, the radial depth of cut $a_{e}$ is the most significant factor, and the axial depth of cut is the least significant factor. The analytical results are corresponding to the previous research conclusion that the chip thickness has a 
direct effect on the cutting process since the chip thickness is decided mainly by the feed given the flute number of the cutter and the spindle speed.

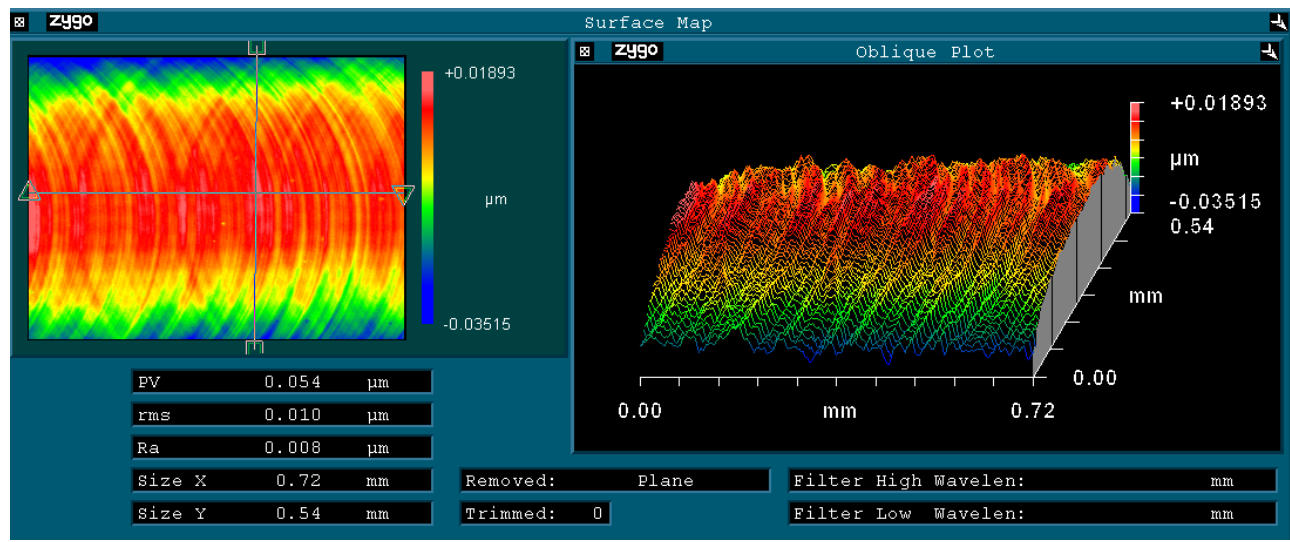

Fig. 7 Surface finish

\section{Summary}

A micromilling machine tool has been designed and developed. Modal analyses of the key parts show that the first several orders of frequencies are relatively larger while the stiffness is higher. The gantry and the $\mathrm{Z}$ slide have the maximum and minimum effects on the whole machine tools' dynamics, respectively. Final accuracy of the developed desktop micromilling machine tool can reach sub micron and experimental results show the feasibility for micromilling applications. The analyses of the experimental results have identified the affecting tendencies of the three key process parameters on the micromilling results of brass H59. It turns out that there exists an optimal axial depth of cut to achieve the best surface roughness while other parameters are given. The radial depth of cut affects the finished surface roughness most greatly. The feed and the radial depth of cut have less significance on the surface roughness. Based on the analytical results, small holes with large aspect ratio are successfully micromilled.

\section{Reference}

[1] X.C. Luo, K. Cheng, D. Webb, F. Wardle, Design of ultraprecision machine tools with applications to manufacture of miniature and micro components, Journal of Materials Processing Technology, 167 (2005) 515-528.

[2] Y. Okazaki, T. Mori, Desk-top NC milling machine with 200k rpm spindle, Proc. ASPE's 16th Annual Meeting, (2001) 192-195.

[3] T. Kitahara, Y. Ishikawa, T. Terada, N. Nakajima, K. Furuta, Development of micro-lathe, Journal of Mechanical Engineering Laboratory, 50(1996) 117-123.

[4] D.A. Axinte, S. AbdulShukor, A.T. Bozdana, An analysis of the functional capability of an in-house developed miniature 4-axis machine tool, International Journal of Machine Tools \& Manufacture, 50(2010) 191-203.

[5] Z.N. Lu, T. Yoneyama, Micro cutting in the micro lathe turning system, International Journal of Machine Tools \& Manufacture, 39(1999) 1171-1183.

[6] T. Schaller, L. Bohn, J. Mayer, Microstructure grooves with a width of less than $50 \mu \mathrm{m}$ cut with ground hard metal micro end mills, Precision Engineering, 23(1999) 229-235.

[7] X. Cheng, K. Nakamoto, M. Sugai, S. Matsumoto, Z.G. Wang, K. Yamazaki, Development of ultra-precision machining system with unique wire EDM tool fabrication system for micro-machining, CIRP Annals -Manufacturing Technology, 57(2008) 415-420. 
[8] W.Q. Chen, Q.S. Bai, K. Yang, Q. Zhang, Y.C. Liang, Dynamics design optimization and experimental validation of a miniaturized machine tool for micro-machining, Prod. Eng. Res. Devel., 2013, DOI 10.1007/S11740-013-0460-8.

[9] S. Filiz, L. Xie, L.E. Weiss, O.B. Ozdoganlar, Micromilling of microbarbs for medical implants, Int. J. Mach. Tools. Manuf., 48(2008) 459-472.

[10] A. Dhanorker, X.Y. Liu, T. Ozel, Micromilling process planning and modelling for micromold manufacturing, Proc. ASME Int. Manuf. Sci. Eng. Conf. MSEC, (2007) 759-769.

[11] M.P. Vogler, R.E. Devor, S.G. Kapoor, On the modelling and analysis of machining performance in micro-endmilling, Part I: surface generation, J. Manuf. Sci. Eng., 126(2004) 685-694.

[12]P. Cardoso, J.P. Davim, A brief review on micromachining of materials, Rev. Adv. Mater. Sci., 30(2012) 90-102.

[13]X. Cheng, L. Li, Y.M. Huang, S.J. Zhou, Z.H. Yang, J.Y. Liu, Study on the error distribution and key parameters for a desktop multi-axis micro milling machine tool, Int J Adv Manuf Technol, 67(2013) 2521-2527. 